\title{
Differential content of glyphosate and its metabolites in Digitaria insularis biotypes
}

\author{
Leonardo Bianco de Carvalho \\ Santa Catarina State University, Centre of AgriVeterinarian Sciences, Department of Agronomy, Lages, SC, Brazil
}

Antonia María Rojano-Delgado

University of Córdoba, High Technical School of Agricultural Engineering and Forestry, Department of Agricultural Chemistry and Edaphology, Córdoba, CO, Spain

Pedro Luis da Costa Aguiar Alves

São Paulo State University, Faculty of Agrarian and Veterinarian Sciences, Department of Biology Applied to Agropecuary, Jaboticabal, SP, Brazil

\section{Rafael De Prado}

University of Córdoba, High Technical School of Agricultural Engineering and Forestry, Department of Agricultural Chemistry and Edaphology, Córdoba, CO, Spain

\begin{abstract}
Experiments were carried out in controlled conditions to analyze the role of metabolism of glyphosate in Digitaria insularis (sourgrass) biotypes with differential response to the herbicide. Contents of glyphosate, aminomethylphosphonic acid (AMPA), glyoxylate, and sarcosine was detected in leaf tissues by using reversed-polarity capillarity electrophoresis. Glyphosate content in the A biotype increased from 19.7 up to $65.5 \mu \mathrm{g} \mathrm{g}$ fresh weight ${ }^{-1}$, whereas decreasing from 19.9 down to $5.0 \mu \mathrm{g} \mathrm{g}$ fresh weight ${ }^{-1}$ in the B biotype, from 48 up to 168 hours after treatment. At 168 hours after treatment, percentage of the sum of AMPA, glyoxylate, and sarcosine was $>56 \%$ in the $B$ biotype, whereas a small percentage of metabolites $(<10 \%)$ was found in the A biotype. Thus, the faster herbicide degradation in the B biotype is evidence that a differential metabolism of glyphosate can be conferring its lesser susceptibility to the herbicide.
\end{abstract}

Keywords: Digitaria insularis, $N$-phosphonomethylglycine, herbicide degradation. 


\section{INTRODUCTION}

Glyphosate ( $N$-phosphonomethylglycine) is the most used herbicide worldwide, having a chemical structure and a molecular target site related to the inhibition of the shikimate pathway, resulting in starvation of 5enolpyruvylshikimate-3-phosphate and ensuing metabolic products, such as the aromatic acids phenylalanine, tyrosine, and tryptophan that are required for protein synthesis (Duke 2011). In addition, the inhibition of the shikimate pathway causes its deregulation, resulting in carbon flux from other pathways, leading to disruption of the other metabolic pathways.

The degradation of glyphosate by plants was not accepted during many years. Most of the early works on the metabolism of glyphosate in crops indicated that glyphosate is metabolized very slowly, if at all (Duke 2011). This general finding fit the fact that glyphosate is a slow-acting, nonselective herbicide. If a plant metabolized the herbicide rapidly, it should have a degree of natural resistance, just as many crops are resistant to the selective herbicides that are used with them by virtue of rapid metabolism. However, most recent researchers have found increased glyphosate degradation in some tolerant and resistant plants (Ulanov et al. 2009, Cruz-Hipolito et al. 2011, Carvalho et al. 2012, González-Torralva et al. 2012, RojanoDelgado et al. 2012).

The objective of this research was to analyze the role of metabolism of glyphosate in Digitaria insularis (sourgrass) biotypes with differential response to the herbicide.

\section{MATERIAL AND METHODS}

Plant material. Seeds from a population of sourgrass plants were harvested from an orange orchard located at $22^{\circ} 26^{\prime}$ '00" S and $46^{\circ} 49^{\prime}$ '18' WGr within São Paulo State, Brazil, in 2009. Sampled population were screened and purified in laboratory conditions using glyphosate at $720 \mathrm{~g}$ ae ha $\mathrm{ha}^{-1}$, and then seeds of the plants surviving were collected and used in this study, hereafter referred to biotype B. In addition, seeds of the species were also collected from natural areas never treated with herbicides located at $22^{\circ} 34^{\prime} 50^{\prime \prime} \mathrm{S}$ and $47^{\circ} 31^{\prime} 07^{\prime \prime}$ WGr, hereafter referred to biotype A.

Growing conditions. Plants were grown in $300 \mathrm{~mL}$ plastic pots maintained in a growth chamber model AM0705020 (Eldon, The Netherlands) at $28 / 18{ }^{\circ} \mathrm{C}$ (day/night) in $16 \mathrm{~h}$ photoperiod under $850 \mu \mathrm{mol} \mathrm{m} \mathrm{m}^{-2} \mathrm{~s}^{-1}$ photosynthetic photon-flux density delivered by a mixture of incandescent and fluorescent lights, with $80 \%$ relative humidity. The substrate contained a $1: 2$ (v:v) mixture of peat and sandy loam and was irrigated by supplying water twice a day and Hoagland nutrient solution a time a week.

Herbicide and spraying conditions. Commercial herbicide formulation with $45 \%$ of isopropylamide salt of glyphosate SL (Monsanto, Belgium) was used in this study. The herbicide was sprayed into plants of both biotypes at the 4-leaf growth stage. Glyphosate applications were performed using a laboratory tracking sprayer model SBS-060 (DeVries, United States of America) equipped with a flat-fan nozzle model 80.02E VS (TeeJet, United States of America), delivering a spray volume of $200 \mathrm{~L} \mathrm{ha}^{-1}$ at $200 \mathrm{kPa}$.

Glyphosate and metabolites detection. A plant per pot was cultivated to metabolic studies of glyphosate degradation by using reversed-polarity capillarity electrophoresis with indirect absorptiometric detection, following the protocol described by Rojano-Delgado et al. (2010). Glyphosate at $157.5 \mathrm{~g}_{\text {ae }} \mathrm{ha}^{-1}$ was applied to plants of both biotypes at the 4-leaf growth stage. Concentration of glyphosate and its metabolites was determined by reversed-polarity capillarity electrophoresis. Glyphosate, aminomethylphosphonic acid (AMPA), glyoxylate, sarcosine, and formaldehyde were detected (using standards for the comparison) in leaf tissues of plants of all biotypes at 48, 96, and 168 hours after treatment with glyphosate (HAT).

Leaf tissues of treated and untreated plants were cut and frozen at $-40 \stackrel{\circ}{\circ}$. Following, frozen samples were washed three times with $20 \mathrm{~mL}$ water to remove traces of glyphosate herbicide and soil in the leaf surface. In total, $1.5 \mathrm{~g}$ sample was placed in the porcelain mortar and flash-frozen using $20 \mathrm{~mL}$ liquid nitrogen. Then, the sample was ground to a fine powder using the porcelain pestle for $5 \mathrm{~min}$, and the powder transferred to a plastic beaker and extracted three times with $8 \mathrm{~mL}$ 1:1 water-acetone, each time involving magnetic stirring for $10 \mathrm{~min}$, ultrasonication for $5 \mathrm{~min}$, and centrifugation at $4 \stackrel{\circ}{ } \mathrm{C}$ and $10,000 \mathrm{rpm}(18,144 \mathrm{~g}$ with a rotor number 20) for $15 \mathrm{~min}$. Following, the supernatants obtained with the three $8 \mathrm{~mL}$ portions of extractant were pooled and evaporated to dryness under air flow. The extract was reconstituted with $2 \mathrm{~mL}$ BGE (10 mM potassium phthalate, $0.5 \mathrm{mM}$ CTAB and $10 \% \mathrm{ACN}$ at $\mathrm{pH} 7.5$ ) and filtered through a nylon filter before capillary electrophoresis analysis.

The filtered extract was injected for $5 \mathrm{~s}$ at $-10 \mathrm{kV}$ into the BGE. The analysis voltage was $-20 \mathrm{kV}$, and the monitoring wavelength $220 \mathrm{~nm}$ for all analytes. Each sample was fortified previously with standards for the correct analysis. In order to maintain the capillary under optimal working conditions, its surface was regenerated after each run by sequential washing with 
water (2 min), $0.1 \mathrm{M}$ sodium hydroxide (2 $\mathrm{min}), 1 \mathrm{~min}$ waiting and BGE (10 min). In addition, the capillary was activated everyday by sequential washing with water (1 $\mathrm{min}), 0.1 \mathrm{M}$ sodium hydroxide (10 $\mathrm{min}), 5 \mathrm{~min}$ waiting and water (1 $\mathrm{min})$. So, electropherograms were obtained and the concentrations of glyphosate and its metabolites were determined based on standard equations as described by Rojano-Delgado et al. (2010).

Experimental design and statistical analysis. Metabolism experiments were arranged in a completely randomized design with three replicates and repeated three times. Data was submitted to previous ANOVA (F-test) to test the interaction between treatments and experimental repetitions. In that case, previous ANOVA was not significant ( $p>$ 0.05 ), so that all data were pooled across experimental repetitions for further analysis and presentation. Following, data of the concentrations of glyphosate and total metabolites were then submitted to a new ANOVA (F-test) and Tukey's HSD post hoc test at the $5 \%$ probability. Statistical analyzes were performed by using software Statistix version 8.0 (Analytical Software, United States of America).

\section{RESULTS AND DISCUSSION}

Biotypes A and B were previously tested for glyphosate response, showing the dose required to reduce the biomass accumulation by $50 \%$ at ca. $64 \mathrm{~g}$ ea ha ${ }^{-1}$ for the A biotype and ca. $149 \mathrm{~g}$ ea ha ${ }^{-1}$ for the $\mathrm{B}$ biotype, so that the resistance factor was 2.3, indicating that the $B$ biotype resisted to doses 2.3 times greater than the A biotype (Carvalho et al. 2011). These authors also observed a higher accumulation of shikimic acid in the A biotype while a slightly concentration of that metabolite was found in the $B$ biotype, indicating that the shikimate pathway was inhibited significantly in biotype A (data not shown), according to the mechanism of glyphosate action in plants (Duke 2011).

In the metabolic studies of glyphosate degradation, percentage of glyphosate, in relation to its metabolites, detected in fresh tissues of biotype $\mathrm{A}$, varies on $81.4 \%$ up to $93.1 \%$, during $48-168$ HAT, showing no difference in time (Table 1). On the other hand, percentage of glyphosate in biotype B showed difference in time, decreasing from $82.6 \%$ (48 HAT) down to $43.5 \%$ (168 HAT). In addition, the content of glyphosate metabolites showed similar results, varying on $6.9 \%$ up to $18.6 \%$, during $48-168 \mathrm{HAT}$, also having no difference in time. On the other hand, percentage of glyphosate metabolites in biotype B showed difference in time, increasing from $17.4 \%$ (48 HAT) up to $56.5 \%$ (168 HAT).
Table 1. Relative percentage of glyphosate and its metabolites (AMPA + glyoxylate + sarcosine) in biotypes A and B of sourgrass (Digitaria insularis) at different hours after treatment (HAT) with glyphosate at $157.5 \mathrm{~g}$ ae ha-1.

\begin{tabular}{llllrl}
\hline Biotype & HAT & Glyphosate & Metabolites \\
\hline & & & & & \\
A & 48 & $81.4 \pm 10.8$ & AB & $18.6 \pm 3.5$ & C \\
& 96 & $93.1 \pm 6.9$ & A & $6.9 \pm 1.4$ & D \\
& 168 & $90.1 \pm 8.1$ & A & $9.3 \pm 1.9$ & D \\
& & & & & \\
B & 48 & $82.6 \pm 5.0$ & AB & $17.4 \pm 8.1$ & CD \\
& 96 & $70.6 \pm 4.1$ & C & $29.4 \pm 4.3$ & B \\
& 168 & $43.5 \pm 5.2$ & D & $56.5 \pm 11.3$ & A \\
\hline
\end{tabular}

In the A biotype, AMPA and sarcosine were not detected up to 96 HAT, while $8.7 \mu \mathrm{g} \mathrm{g}^{-1}$ of AMPA and $1.2 \mu \mathrm{g} \mathrm{g}^{-1}$ of glyoxylate were found in the B biotype (Figure 1). In addition, $2.3 \mu \mathrm{g} \mathrm{g}^{-1}$ of sarcosine was also detected in the resistant biotype at 96 HAT. At $168 \mathrm{HAT}, 4.6 \mu \mathrm{g} \mathrm{g}^{-1}$ of AMPA and $2.1 \mu^{\mathrm{g} \mathrm{g}} \mathrm{g}^{-1}$ of glyoxylate were detected in $A$ biotype, indicating slightly degradation of glyphosate, but, in the B biotype, glyphosate was degraded to AMPA $\left(5.8 \mu \mathrm{g} \mathrm{g}^{-1}\right)$, glyoxylate $\left(0.4 \mu \mathrm{g} \mathrm{g}^{-1}\right)$, and also sarcosine $\left(0.3 \mu \mathrm{g} \mathrm{g}^{-1}\right)$ faster than in the $\mathrm{A}$ biotype.

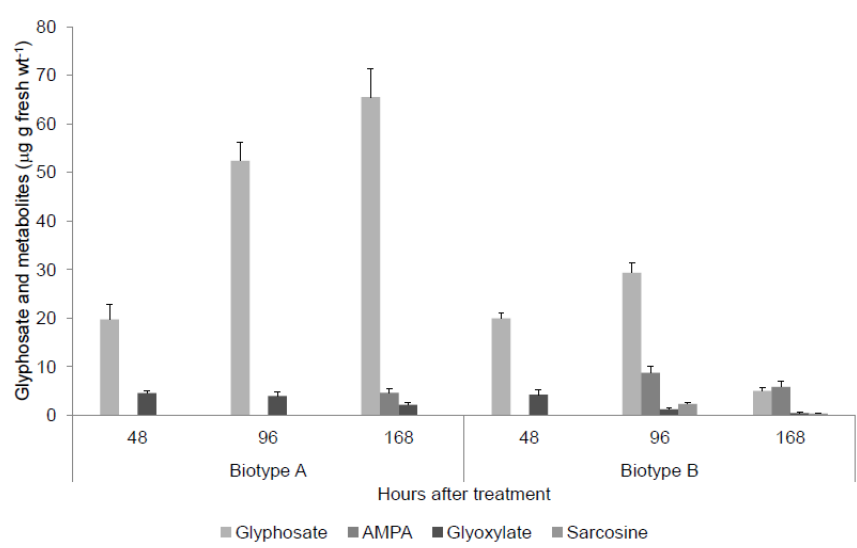

Figure 1. Content of glyphosate, aminomethylphosphonic acid (AMPA), glyoxylate, and sarcosine detected in leaves of biotypes A and $B$ of sourgrass (Digitaria insularis) at different hours after treatment with glyphosate at $157.5 \mathrm{~g}$ ae ha- ${ }^{-1}$.

Results of metabolism studies showed very significant differences between biotypes $A$ and $B$. Differences in contents of glyphosate, AMPA, glyoxylate, and sarcosine between biotypes $A$ and $B$ were strong evidences that differential herbicide metabolism was, at least in part, playing an important role in the response of the $B$ biotype to glyphosate. Specifically, the accumulation of glyphosate in the A biotype and the appearance of AMPA, glyoxylate, and sarcosine as well as the decreasing of glyphosate content in the $\mathrm{B}$ biotype were evidences that glyphosate was degraded by the $B$ biotype much faster than the A biotype.

Degradation of glyphosate was reported in other sourgrass biotypes (Carvalho et al. 2012) and biotypes of Conyza canadensis (González-Torralva et al. 2012) resistant to glyphosate. Moreover, other authors 
working with glyphosate-tolerant plants (Ipomoea purpurea, Convolvulus arvensis, Clitoria ternatea, Neonotonia wightii, Zea mays, and Mucuna pruriens) have demonstrated the ability of some plants to metabolize glyphosate to AMPA, sarcosine, and glycine (Sprankle et al. 1978, Sandberg et al. 1980, Cruz-Hipolito et al. 2011, Ulanov et al. 2009, RojanoDelgado et al. 2012).

Two metabolic pathways are known for glyphosate degradation in living organisms (Schuette 1998, Duke 2011). A first degradation pathway involves the herbicide degradation by glyphosate oxidoreductase (GOX) enzyme action, producing AMPA and glyoxylate (Duke 2011). AMPA is the main metabolite originated from glyphosate degradation, whereas glyoxylate, despite being a metabolite derived of glyphosate degradation, is also a plant endogenous metabolite involved in different metabolic pathways (RojanoDelgado et al. 2010). AMPA is degraded to methylamine by C-P lyase enzyme action, and by methylamine dehydrogenase enzyme action, methylamine generates formaldehyde (Schuette 1998). A second pathway is glyphosate degradation to sarcosine by direct C-P lyase enzyme action (Duke 2011).

The appearance of those metabolites in plants is evidence that glyphosate was been degraded, but it does not explain how or by what the herbicide was degraded. Thus, although metabolism of glyphosate by sourgrass plants is confirmed, further investigations must be carried out to analyze the role of the enzymes involved in the glyphosate degradation or even if other agent (e.g. microorganisms) could be responsible to the herbicide degradation.

\section{CONCLUSION}

Taken together the results of this research allow us to conclude that faster herbicide degradation by the $\mathrm{B}$ biotype is evidence that a differential metabolism of glyphosate can be conferring its lesser susceptibility to the herbicide.

\section{Acknowledgments}

Authors thank Governments of Brazil (the Brazilian SWE/CNPq project 201417/2009-0) and Spain (the MICINN project AGL2010-16774) for financial support.

\section{References}

Cruz-Hipolito H, Rojano-Delgado A, Domínguez-Valenzuela JA, Heredia A, Luque de Castro MD, De Prado R. 2011. Glyphosate tolerance by Clitoria ternatea and Neonotonia wightii plants involves differential absorption and translocation of the herbicide. Plant Soil 347: 221-230.
Carvalho LB, Cruz-Hipolito HE, González-Torralva F, Alves PLCA, Christoffoleti PJ, De Prado R. 2011. Detection of sourgrass (Digitaria insularis) biotypes resistant to glyphosate in Brazil. Weed Sci 59: 1711-1776.

Carvalho LB, Alves PLCA, González-Torralva F, Cruz-Hipolito HE, Rojano-Delgado AM, De Prado R, Gil-Humanes J, Barro F, Luque de Casto MD. 2012. Pool of resistance mechanisms to glyphosate in Digitaria insularis. J Agric Food Chem 60: 615-622.

Duke SO. 2011. Glyphosate degradation in glyphosate-resistant and -susceptible crops and weeds. J Agric Food Chem 59: 5835-5841.

González-Torralva F, Rojano-Delgado AM, Luque de Castro MD, Norbert M, De Prado R. 2012. Two non-target mechanisms are involved in glyphosate-resistant horseweed (Conyza Canadensis L. Cronq) biotypes. J Plant Physiol 169: 1673-1679.

Rojano-Delgado AM, Ruiz-Jiménez J, Castro MDL, De Prado R. 2010. Determination of glyphosate and its metabolites in plant material by reversed-polarity CE with indirect absorptiometric detection. Electroph 31: 1423-1430.

Rojano-Delgado AM, Cruz-Hipolito H, De Prado R, Luque de Castro MD, Franco AR. 2012. Limited uptake, translocation and enhanced metabolic degradation contribute to glyphosate tolerance in Mucuna pruriens var. utilis plants. Phytochem 73: 34-41.

Sandberg CL, Meggitt WF, Penner D. 1980. Absorption, translocation and metabolism of ${ }^{14} \mathrm{C}$-glyphosate in several weeds species. Weed Res 20: 195-200.

Schuette, J. 1998. Environmental fate of glyphosate. DPR, Sacramento.

Sprankle P, Sandberg CL, Meggitt WF, Penner D. 1978. Separation of glyphosate and possible metabolites by thin-layer chromatography. Weed Sci 26: 673-674.

Ulanov A, Lygin A, Duncan D, Widholm J, Lozoyaya V. 2009. Metabolic effects of glyphosate change the capacity of maize culture to regenerate plants. J Plant Physiol 166: 978-987. 